\title{
Leadership challenges in health care organizations: The case of Iranian hospitals
}

\author{
Maryam Ghiasipour ${ }^{1}$, Ali Mohammad Mosadeghrad ${ }^{1}$, Mohamad Arab ${ }^{1}$, Ebrahim Jaafaripooyan ${ }^{1}$
}

Received: 11 Mar 2017

Published: 17 Dec 2017

\begin{abstract}
Background: Effective leadership is a vital component of health care systems and has an extensive range of functions in improving organizational effectiveness and efficiency. This study aimed at exploring leadership challenges encountered by leaders in Iranian hospitals.

Methods: This qualitative study was conducted on a purposeful sample of 27 members of hospital management team in Tehran using face-to-face semi-structured interviews and in-depth interviews. Thematic analysis was used to analyze and report the data.

Results: In this study, 5 main themes emerged upon the challenges of leadership in health care organizations as follow: organizational structure (complexity, centralization, and bureaucracy); human resources (the number and distribution of human resources, staff empowerment, and education, motivational mechanisms, and staff diversity); work nature (sensitivity, stress and tension, customer diversity, and team- oriented); leaders (knowledge and skills, appointment, superiors and colleagues, and time); and context (regulations and programs, cultural issues, social issues, and economic issues).

Conclusion: The results of this study shed some light on the leadership challenges in a culturally specific developing country. The results also proved the importance of using educated leaders who are capable of understanding, analyzing, and dealing with such complex challenges.
\end{abstract}

Keywords: Leadership, Challenge, Hospital, Health Care organization, Iran

Copyright@ Iran University of Medical Sciences

Cite this article as: Ghiasipour M, Mosadeghrad AM, Arab M, Jaafaripooyan E. Leadership challenges in health care organizations: The case of Iranian hospitals. Med J Islam Repub Iran. 2017 (17 Dec);31:96. https://doi.org/10.14196/mjiri.31.96

\section{Introduction}

Health care organizations (HCOs), with hospitals at the center, are considered as large and complex contemporary organizations, owing to their advanced procedures and different resources (1). HCOs' performance depends on knowledge, skills, and personal incentives of human resources (2-4). Given the importance of this resource, a consistent leadership is needed to achieve high performance and enhance employees' capabilities to improve the quality of care and outcomes $(5,6)$. Leading quality improvement process requires leaders who manage uncertainty and foster cultural and behavioral changes (7-9).

Leadership is a long-term process of influencing people toward accomplishing a mission and particular goals of a group or an organization (10). This process sets goals and strategies, enhances commitment and compliance to ob-

Corresponding author: Dr Ebrahim Jaafaripooyan, jaafaripooyan@tums.ac.ir

1. Department of Health Management and Economics, School of Public Health, Tehran University of Medical Sciences, Tehran, Iran. jectives and organizational productivity, and promotes the culture of team and dynamicity in organizations $(11,12)$. It is also a timeless practice of structuring or restructuring the conditions and members' perceptions and expectations $(13,14)$. Studies have revealed that most of the problems of health care systems are due to poor communication and leadership $(1,15)$. Poor leadership in HCOs could increase costs, reduce efficiency and effectiveness, and cause dissatisfaction among staff, ultimately resulting in lower patient satisfaction and society health level (16-19). Appropriate leadership can create an organizational culture that is committed to quality, reducing conflicts, improving efficiency and productivity of teams, enhancing staff's satisfaction, advancing hospital performance, and finally, meeting personal and organizational goals $(20,21)$. Most

$\uparrow$ What is "already known" in this topic:

This was the first exploratory attempt to identify the leadership challenges in hospitals in Iran that were not addressed by previous literature.

\section{$\rightarrow$ What this article adds:}

This study revealed the challenges to the effective leadership in Iran's hospitals, such as dealing with organizational structure and human resources, issues related to the leaders, work nature, and contextual effects. 
leadership studies have been conducted in developed countries and in the areas outside health care, and only a very few has been done in the realm of health care $(22$, 23 ). Given the prominent role of context in the sense that national culture, public laws and socioeconomic status might influence managers' behavior and their leadership style and considering the shortage of studies in health care, there is an urgent need for similar studies in developing countries (24).

Despite the presence of the complex challenges in managing health care organizations in developing countries, not enough studies have been done in these countries (25). Most of the leadership related studies that have been performed in Iran investigated the leadership style and its impact on such issues as efficiency and operational indicators of hospitals, job satisfaction, conflicts management, staffs' motivation, creativity, and etc. (26-29). Some have further investigated the transformational, ethical, charismatic, spiritual, and other prominent hospital leadership models, while most have been conducted on limited hospital settings (30-35) .

Therefore, there is a gap in integrated studies to investigate and recognize the challenges of leadership in Iranian health care system (IHCS). Qualitative studies, as an effective approach, are expected to provide in-depth and objective views on the real experiences of leaders in this sector. The current study has been conducted to explain the obstacles and challenges of leadership in Iranian HCOs to help identify the problems, and thereby develop the appropriate operational and applicable solutions for effective leadership in HCOs of IHCS.

\section{Methods}

\section{Study design}

A qualitative approach was employed to obtain an indepth view on contextual issues of leadership, explore the new aspects of leadership, and examine the leadership challenges in Iranian HCOs. This study was conducted in 2016.

\section{Setting and sampling}

Participants were hospital managers working at different managerial levels in hospitals located in Tehran, Iran. The main inclusion criterion was having at least five years of managerial experience.

\section{Data collection}

Data were collected using semi-structured, in-depth interviews. Although a general interview guide was used, most interviews were conducted based on interviewee's individual characteristics. Therefore, the time, questions, and wording of each interview were flexible to increase the depth and volume of the collected data. All interviews were recorded by interviewee's permission and transcribed. Three interviewees denied voice recording, and a person was employed to write down their interviews. The average length of interviews was between 40 to 60 minutes. The time and place of interviews were determined by the interviewees. Data collection continued until data saturation was reached, which was after 27 inter- views.

\section{Data analysis}

Data were collected and analyzed simultaneously, and the thematic analysis framework was employed. Codes were derived in an inductive procedure using open coding. Then, categories and themes were defined based on the similarities and differences. MAXQDA10 was used for facilitating the data analysis process.

\section{Trustworthiness of research}

To increase the credibility of the findings, enough time was spent to collect and review data frequently using a variety of sampling methods (selecting participants from different managerial levels and organizations) and giving feedback to the participants. In case of any discrepancies between the text of the interview and the participants' feedback, all items were reviewed. In addition, vague issues were clarified through further phone contact. Audit trial was used to assure the dependability of the findings. Besides, 2 faculty members, who were experts in qualitative research, analyzed and reviewed the handwritten interviews to ensure the dependency of contents and results.

\section{Ethical considerations}

The participants were provided with sufficient information about the objectives of the study, data confidentiality, and the optional nature of the study. Also, their informed consent was obtained.

\section{Results}

The age range of all 27 interviewees varied from 40 to 59 years, they had 7 to 26 years of management experience, and of them 16 were male. Among the participants, there were 1 hospital director, 9 hospital managers, 6 nursing administrators (matrons), 3 administrative-financial managers, and 8 supervisors, working in public, private, and social security hospitals.

According to the results, leadership challenges in Iran's hospitals were classified into 5 main categories including organizational structure, human resources, issues related to the leaders, work nature, and context (Table 1).

\section{Organizational structure challenges}

Interviewees stated that the existence of various professions in hospitals can increase specialization and horizontal differentiation and may cause conflicts in communication and coordination.

"It is difficult to coordinate people in such diverse sections, as each of them considers the problems differently. For example, the way the accounting staff looks at the problems is different from the way the nursing personnel or physicians consider them.... The emergency physician considers a series of experiments immediate, but the laboratory staff has the opposite idea. This great diversity of expertise results in many conflicts...." (p4)

Managers' insufficient authority to recruit, relocate, promote, and dismiss the personnel, as well as their limited authorities to apply motivational and welfare programs, decreases their power and influence. On the other 
Table 1. Leadership challenges in Iranian health care organizations

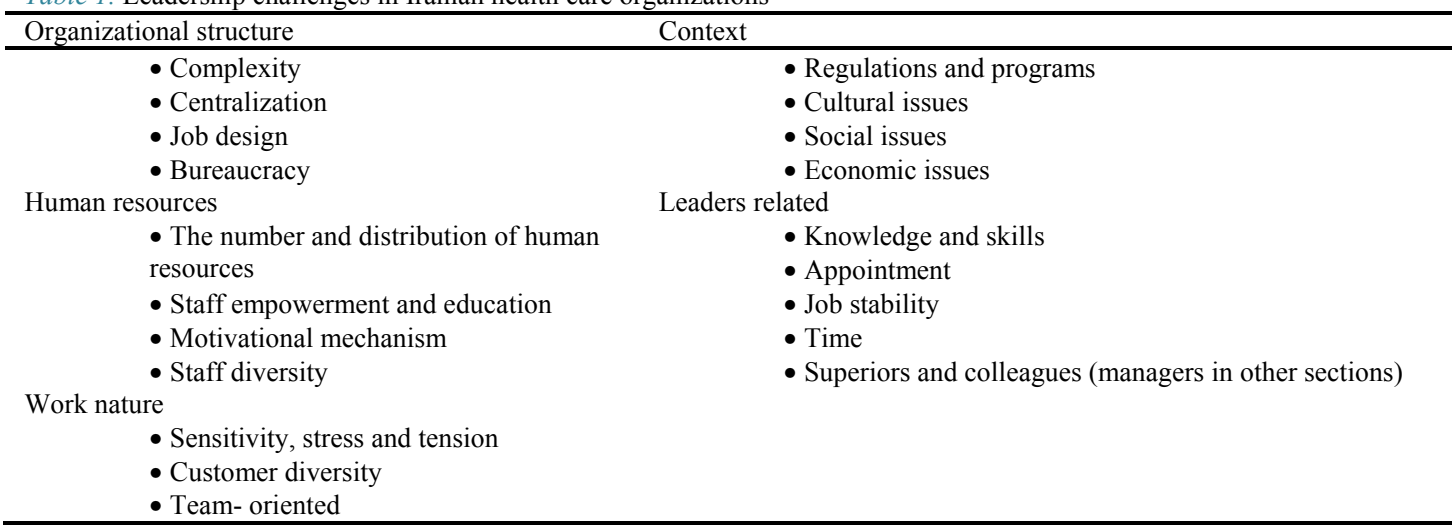

hand, it limits the efforts to improve leader-follower relationship and minimizes job satisfaction.

"Sometimes, I have to work with people who are not a good match for the system and their job, but I don't have enough authority to relocate them....In addition, most of the time, I don't have the power to promote a competent employee...." (p27)

Vague and inadequate job descriptions and specifications is another structural challenge.

"Job specification has not been developed properly and a large number of people are not fit for their jobs in terms of both their characters and abilities; and this causes stress, tension, and conflicts with coworkers and supervisors.... More conflicts seen between my employees are because of vague job descriptions, as there are overlaps and conflicts in job descriptions...." ( $p 8)$

Participants stated that the lack of financial resources and its negative effects on the activities of the hospital and also on bonus and welfare facilities has led to conflicts of interests and inconsistencies.

"If adequate financial resources are injected on time, jobs are done much better, subordinates will have no problems with each other, and we can have better plans for remuneration and welfare programs.... As the saying goes "money brings power and influence." (p21)

Old buildings with unfavorable conditions in terms of light, space, and location, as well as the lack of equipment and accessories have caused stress and conflict. They were considered physical resources challenges by the participants due to their impacts on work process and personnel's satisfaction.

"The hospital building is old and small; owing to its bad plan, connection and coordination is difficult. This problem along with the lack of equipment slows down work and causes many conflicts.... Personnel's morale is bad because of working in this old and boring place.... The best incentive is to make working places safe and appropriate.... (p16)

Bureaucracy in hospital wastes personnel and managers' time and reduces the time spent for adequate and appropriate communication among employees, leaders, and followers.

"Especially after the implementation of the hospital accreditation, we have so much documentation and paperwork to do, and thus the staffs, especially, the nurses do not have time to do their main work... I myself have so much paperwork to do that I can't find time to have faceto-face meetings with my personnel." (p19)

\section{Human resources challenges}

Participants considered the shortage of manpower and its improper distribution a major problem in the leadership. Owing to increased workload, the shortage of manpower increased tensions and conflicts on the one hand and decreased the opportunity to establish friendly relationships between the personnel and supervisors on the other hand.

"Concerning our workload, we don't have enough personnel, and this shortage increases work pressure and the personnel are often tired and nervous and have conflicts.... On the other hand, we have to use people who are not suitable for the job and who are sometimes uninterested in their jobs. Such people always have problems in their jobs and in their relationships with others." (p1)"

Another issue about human resources is inappropriate pre-employment and on-the-job education in terms of amount, content, and sometimes unskilled educators.

"Training courses are not enough for the personnel, and the existing courses are not suitable in terms of content.... Most of the staff are not aware of their duties and administrative rules, and this could cause serious problems in communication and work process ...." (p10)

One of the most important leadership challenges was inappropriate motivational mechanism in the hospitals. The disproportionate remuneration, appointment, and promotion to the personnel's performance, ignoring individual differences in applying motivations, and also unstable and inadequate bonus cannot stimulate people.

"This evaluation system does not show the performance of personnel.... When my boss forces me to give all my subordinates almost the same scores to avoid objections, the one who is doing well gets disappointed.... When the employees' performance has no effect on their payment and promotion, how can we encourage them to have better performance?" (p12)

Another leadership challenge in the hospital is the wide diversity of hospital staff in terms of education level, profession, social class, and income, as well as the need to recognize these differences to apply motivational and leadership techniques proportional to different people. 
"We have multifarious employees with different needs and motives (from faculty members to servants).... It is difficult to recognize their attitudes and satisfy them...." (p18)

\section{Work nature challenges}

One of the challenges mentioned in this study was the work nature in the hospital, its sensitivity, and the stress and tension involved. Continuous confrontation with unpredictable problems and crises, the need for quick decisions, professional risks in health jobs, rotation of working hours, high workloads, and most importantly dealing with peoples' lives were regarded as the main reasons for high sensitivity of hospital jobs and tensions caused by them.

"Stress is high at the hospital, especially in the treatment wards, either for staff or supervisors.... The issue is not just changing the papers; it is about the people's lives.... ( $p 7)$;

In addition to the heavy workload, shift work and nighttime awakenings cause tension, exhaustion, and irritability.... On the other hand, shift work causes a person to have different supervisors in different shifts and decreases mutual communication and interactions ...." (p25)

Most participants believed those variations in patients and their companions in terms of disease; social class, income, and culture required manpower with special mental and spiritual abilities on the one hand and caused tensions and conflicts in the work place on the other hand; so it required intelligent leadership and special motivational methods for dealing with this condition.

"My personnel not only need professional skills but also must have close relationship with patients and their companions from different classes who are mainly unaware of the specialized treatment measures....This is a stressful and grueling process...." (p20)

The teamwork- oriented nature of hospital process and consequently high levels of personnel's work dependency concerning the diversity of team members increased conflicts and challenges in leadership.

"The problem is that we cannot reduce these conflicts by establishing independency and decreasing the necessity of communication .... Perhaps no workplace needs such teamwork...." (p5)

\section{Context related challenges}

Troublesome rules, insufficient support and supervision rules in the field of manpower, overlaps, and sometimes conflicts between the rules and programs, and frequent changes in determined legislation and programs were some of the challenges related to regulations and programs.

"Human and financial resources' rules and regulations change frequently, making us losing the stability of the processes.... Most of the time, when we finish a huge part of a job, a new opposing rule is passed.... It confuses the personnel and minimizes their motives." (p4)

"Cumbersome rules are one of our problems. For example, there are many restrictive rules to give a bonus, and it requires much paperwork and signatures...." (p 11)

Cultural challenges at 2 national and organizational lev- els were one of the most important challenges mentioned in this study. Individualism, desire for power distance, academic credentials, intolerance of criticism, some cultural limitations, and uselessness of some traditional values in the society were the issues related to the national culture. Moreover, poor teamwork, the prevalence of flattery, low motivation, lack of mutual trust, and a desire to make short-term results were considered the challenges associated with the organizational culture.

"Unfortunately, we are not trained from our childhood on teamwork; we are not trained how to work together and how to accept and manage the differences and conflicts.... (p 19)

Our people always respect those who have a higher level, special position, better certificate, and who keep distance a bit .... If you don't keep a specified distance in relationship with your subordinates, you will lose your influence and charisma, they don't listen to you anymore...." (p15)

Unfortunately, respecting each other, especially elders, respecting women and the value of forgiveness are fading away.... It affects the organization, results in self-service and conflicts, and causes employees not to listen to their bosses...." (p6)

"In having close relationships with our female employees, within the law, we face many difficulties ...." (p22)

Participants believed that social issues affected tensions and conflicts in the hospital, personnel's priorities, and incentives and also the leadership in the system.

"Busy cities, traffic, and consequently the distance from home, air pollution and stress affect the quality of life and morale of employees.... Nowadays, the personnel have many problems compared to the time when I was a director of a hospital in a small town." ( $p$ 25)

Unlike us, the new generation lives in houses with few children, they are always at the center of attention, and they have everything they want. They can't stand difficulties and they don't know how to get along with others ...." (p7)

Most of participants believed that the economic situation with its effects on the organization, staff and patients was one of the most important challenges in the hospitals. Economic problems related to employees affected their morale, abilities, and motivation and having second jobs, which could affect the lives, problems, and diseases of the people. These problems may increase the tensions and conflicts in the workplace and may cause higher workload and issues caused by them.

"Employees need money to live and survive to be satisfied and work properly. When they do not have enough money, how can I motivate them by written letters of appreciation? ... A patient who, in addition to his disease, is faced with treatment expenses will have difficulties in developing relationship with the personnel.... The work place is in chaos...." (p14)

\section{Challenges related to leaders}

One of the main leadership problems was the managers' unfamiliarity with leadership and organizational behavior techniques because of inadequate on-the-job training 
courses, and in many cases, managers' disbelief in the effectiveness and necessity of learning these techniques.

"Among my colleagues, I know many managers, whose majors are not management, and who have not studied any book about management. Most of them believe that these issues are theoretical and can't be applied in the real world." (p11) Most of the interviewees believed that there were many managers in the health system who had been selected as the manager just due to some reasons including relationships with senior managers and length of employment, while they were not qualified enough to lead the staff and the organization concerning both characters and skills.

"Here, we have a supervisor, who is a relative of one of the shareholders. He is not a good leader and cannot maintain a relationship with the staff. He always has problems with his personnel and we are not allowed to relocate him...." (p 24)

Frequent changes of managers caused leaders and followers not to have a chance to know each other and this decreased the opportunity to plan and implement longterm educational and motivational programs. On the other hand, instability of managers undermined leaders' power and influence, which is one of the most fundamental factors of leadership.

"Everything we want to do to improve the situation including staff is time-consuming. When we are not sure how long we have this post, unconsciously we lose our motivation to have long-term plans...." (P9) "When the personnel know that you, like previous managers, would not hold this position for a long time, they do not count on you and don't try to keep you satisfied, and they aren't afraid of your dissatisfaction." (p17)All participants stated that lack of senior managers' support was one of the main challenges in the leadership process.

"Sometimes, I have to substitute an employee because of the system, but he goes to my senior managers and then my decision is revoked, or I promise a diligent employee one bonus or promotion to motivate him, but the senior managers cancel my decisions. " (p15)

Many managers mentioned that they were under direct or indirect pressure of their colleagues (managers of other hierarchies) and bosses in selecting their leadership style and motivational programs.

"Sometimes, I want my employees to collaborate more with me and I want to have a flexible work environment, but my bosses warn me quickly because they do not accept this manner or my coworkers in other sections feel a risk. Thus, I have to follow my boss leadership style." (P24)

When I see that another supervisor gives full bonus to his employee, who works less than my employee, I have no choice but to give my employee full bonus too. Then, payments are not based on performance, and overtime they cannot be used as a motivational tool... (P17)

The findings revealed that time limits and busy managerial jobs caused managers not to have enough time for their leadership duties alongside other administrative tasks.

"I even have less time to solve urgent and critical problems in the hospital as I always have to attend committees and ..., I do not have the time to have a closer relationship with my employees and to know their personalities, needs, and motivations...." (P26)

\section{Discussion}

The present study aimed at investigating the leadership challenges in Iran's hospitals. Five major leadership challenges were found in hospitals including factors related to the context, work nature, human resources, organizational structure, and leaders themselves. There is no comparable science of managing, as leadership is conditional upon specific situations and contexts (36). Studies have revealed that contextual factors such as socioeconomic and political factors had huge effects on the leadership process and outcome in the hospital (37). Effective leadership must focus on dynamic relationships between the values of leadership, culture, organizational capabilities, and context. Successful leaders have a good relationship with the external environment and a broader society (38). Paying attention to the cultural, ethnic, social and gender-based differences of employees and customers (the society) is vital in leadership (39). However, previous studies have revealed that there is no best way to develop leadership, and a suitable leadership development program is contextsensitive. Many studies revealed that paying less attention to the context in leadership significantly reduced the effectiveness of leadership (40). Similar to the results of the present study, those of Calin's study suggested that the major challenges in hospitals were conditions of the context and ignoring them in leadership measures (41). Economic factors, such as problems related to inflation, cost of living, low salaries, and benefits were the main causes of stress and conflicts in Iran's hospitals (42). Moreover, economic problems had negative effects on funding necessary facilities and equipment and caused conflicts and tension at workplace. Economic problems also limited the implementation of welfare programs and adoption of appropriate incentives and motives. Social factors, such as increased migration to the cities, and diversity of people with different situations, religions, cultures, and social conditions, caused conflicts and problems in the hospital system on the one hand and caused many challenges for leaders in adopting appropriate motivational methods due to individual differences of the staff on the other hand. High levels of people's lives, changes in their employees' lifestyles, and family occasions brought about new issues in the field of needs, communication, motivations, and coordination for leaders.

Culture is a fundamental concept in organizational behavior and leadership. Several studies have revealed that presence of a strong positive culture underpinned the realization of different concepts, such as quality, entrepreneurship, and increased organizational performance (43). In his study, Davis argued that cultural traits valued by the leader had a direct and special connection with the organization outcome (44). Many studies conducted in Iran considered national and organizational culture as one of the main challenges in the field of leading different parts of a hospital. Some studies examining the culture in Iran's hospitals concluded that some dimensions of organiza- 
tional culture including creativity, entrepreneurship, risktaking, coherence, and conflict tolerance were lower than the desirable levels, while control and supervision levels were higher than the desirable levels $(45,46)$.

Another challenge mentioned here was the work nature in the health system and hospital. Health care systems are comprised of multiple professional groups and specialties with complex and nonlinear interactions (38). The unique complexity of this system was the result of issues arising from various disease areas, multiple goals, and multidisciplinary staff. Duties of the professional staff in specialized areas caused some problems for the leaders. On the other hand, the goal of hospitals is to provide services related to human life; life and death nature of work in a hospital would increase work sensitivity, stress, and tension in the workplace (47). High work sensitivity, high risk, and consequences resulted from mistakes in decisions and existence of unexpected issues at work caused high work stress and tension in the hospital workplaces and led to many challenges in the field of communication and stressful staff leadership in these centers.

The need for professional employees in various specialized departments and units causes a serious challenge for hospital leadership in recruiting high-quality and diverse human resources.

David Reyes found that the shortage of resources including human resources and inadequate human resource empowerment programs were leadership barriers in public health and health system(48). The shortage of manpower is considered as an obstacle to improve health care in developing countries. Leadership problems are not only related to the quality and distribution of human resources. Low motivation of personnel and inadequate educational programs were also regarded as the major challenges to health care objectives and the leadership of this system(49). In his study in Iran, Nasiri stated that some factors, such as salary and wages, job security, fringe benefits, and a sense of responsibility at work, were the most important motivational factors, and thus they could lead staff towards achieving hospitals objectives. He also proposed that improving the employee empowerment programs, evaluation systems, and reward system were the effective factors in improving employees' performance and incentives (27).

The organizational structure highlights formal and informal communication patterns and power relations as a key leadership element, which allows the managers to determine the behavior and performance of their employees and affect their motivation and productivity directly or indirectly through choosing different organizational structures (50). HCOs, especially in low- and middle-income countries, are one of the institutions with the highest bureaucracy and the least effective management in the public sector. They have changed into highly centralized and hierarchical bureaucracies and have partial and boring executive rules, with permanent staff working in these institutions $(39,51)$. Existence of numerous professionals in the hospitals that require specialized knowledge and skills makes the organization more complicated because people's different positions retard the communication and makes it difficult to coordinate people and processes. As the organizational hierarchy levels increase, the organizational complexity also increase which might distort the leadership communication and coordination. Establishing suitable communication networks causes effective communication between employees, improves team performance, reduces problems and tensions between personnel, and facilitates the identification of personnel's motivational factors, needs and problems by improving followerleader relations (50). Structural weakness and its communication problems, unclear organizational goals, lack of accountability, and poor teamwork are the barriers to effective leadership $(53,54)$. In his study, Fleming stated that structural factors along with the shortage of resources, lack of professional training, and support of the leaders were the most important factors in undermining the quality of leadership (56). Many studies have shown that the concentration of decision-making and authority in the health care system reduces motivation and job satisfaction and has a negative effect on the performance of health personnel (53). Another study in Iran revealed that managers' limited authority and unclear responsibilities, powers, and duties were the main factors causing stress in managers (55).

One of the main challenges mentioned in the leadership process was the leaders themselves. Dye \& Garman stated that one of the biggest challenges of the health system in the coming decades would be the selection and development of leaders who are trained and prepared for leading in the complex health system so that they can, by relying on their proper and accurate leadership skills, reduce the cost of health care system and enhance the achievement of the objectives(56). Many studies have been conducted on the competencies required for leadership in the health care system; some of these features are creativity in solving problems, risk-taking, being interested in developing others, having effective communication and teamwork skills, being educated, and experienced in leadership and work field $(47,57)$. Reyes regarded leaders' commitment to long-life learning (formal and informal education) and stable organizational support as the priorities in the leadership of the health system (48). Fleming regarded poor professional mentorship and the lack of executive support as the effective leadership challenges (54). Reyes mentions that it is necessary to support leaders and their decisions to overcome the professional conflicts and apply effective leadership. The positive effects of empowering and training leaders are remarkable in all 3 personal, organizational, and customers' areas (48). In his study, Mac Alerny found that leaders training and development programs improved workforce capacity, decreased turnover and its expenses, and caused the organization to focus on its objectives and strategies (58). Inadequate leadership skill training leads to rework, high personnel costs, and it ultimately decreases efficiency and effectiveness of organizations. Also, it forces leaders to seek training opportunities outside the organization, which causes some problems, such as interference, loss of time, increased probability of not receiving related, and context-driven training (40). 
Similar to other qualitative studies, in this study, the little possibility of generalizability and difficulty of access to the managers given their shortage of time could be mentioned as research limitations and difficulties.

\section{Conclusion}

This research revealed the challenges and barriers to an effective leadership in Iran's hospitals. Knowledge to such obstacles might help improve leadership and subsequently hospital performance. In addition to an emphasis on the urgent need to effective organizational leadership in Iran's hospitals, the followings should also be addressed: an earnest attention to law enforcement, reviewing health system structure, changing hospital recruitment and appointment policies, effective performance evaluation, performance-based payment systems, need-based and professional educational programs, in-service employee training, empowerment programs, and workable motivational mechanisms. Therefore, the results of this study can be beneficial to policy makers, human resource managers, educational planners, and leaders at all health system levels.

\section{Acknowledgement}

This study was part of a $\mathrm{PhD}$ thesis supported by Tehran University of Medical Sciences (TUMS); grant no. 9021383004.

\section{Conflict of Interests}

The authors declare that they have no competing interests.

\section{References}

1. Weberg D, editor Complexity leadership: A healthcare imperative. Nursing forum; 2012: Wiley Online Library.

2. Storey J, Holti R. Towards a New Model of Leadership for the NHS. 2013.

3. Dinh JE, Lord RG, Gardner WL, Meuser JD, Liden RC, Hu J. Leadership theory and research in the new millennium: Current theoretical trends and changing perspectives. LQ. 2014;25(1):36-62.

4. Mosadeghrad AM. Strategic collaborative quality management and employee job satisfaction. IJHPM, 2014; 2 (4): 167-174.

5. Baker G. The roles of leaders in high-performing health care systems. Paper commissioned by The King's Fund, United Kingdom; 2011.

6. McDermott AM, Keating MA, Leggat SG, Balding C. Achieving organisational competence for clinical leadership: the role of high performance work systems. JHOM. 2013;27(3):312-29.

7. Hardacre J, Cragg R, Shapiro J, Spurgeon P, Flanagan H. What's leadership got to do with it? Exploring links between quality improvement and leadership in the NHS. The Health Foundation, London. 2011.

8. Chen CY, Chen CHV, Li CI. The influence of leader's spiritual values of servant leadership on employee motivational autonomy and eudaemonic well-being. JRH. 2013;52(2):418-38.

9. Mosadeghrad AM, Ferdosi M, Afshar H, \& Hosseini-Nejhad M. The impact of top management turnover on quality management implementation. Med Arh. 2013; 67(2): 134-140.

10.Tingvoll W-A, Sæterstrand T, McClusky LM. The challenges of primary health care nurse leaders in the wake of New Health Care Reform in Norway. BMC nursing. 2016;15(1):66.

11. Arroliga AC,Huber C,Myers JD, Dieckert JP, Wesson D.Leadership in health care for the21st century: challenges and opportunities. AJM. 2014;127(3):246-9.

12. Martin GP, Learmonth M. A critical account of the rise and spread of 'leadership': the case of UK healthcare. Soc. Sci. Med. 2012;74(3):281-8.
13. VanVactor JD. Collaborative leadership model in the management of health care. JBR. 2012;65(4):555-61.

14. Dansereau F, Seitz SR, Chiu C-Y, Shaughnessy B, Yammarino FJ. What makes leadership, leadership? Using self-expansion theory to integrate traditional and contemporary approaches. LQ 2013;24(6):798-821

15.Vaghee S, Yavari M. The effect of communication skills training on the quality of nursing care of patients. EBCJ. 2013;2(4):37-46.

16. Mosadeghrad AM, Yarmohammadian MH. A Study of relationship between managers' leadership style and employees' job satisfaction, Leadersh Health Serv, 2006; 19 (2): 11-28.

17. Mosadeghrad AM, Ferdosi M. Leadership, job satisfaction and organizational commitment in healthcare sector: Proposing and testing a model. Mat Soc Med. 2013; 25(2): 121-126.

18. Rabarison K, Ingram RC, Holsinger Jr JW. Application of situational leadership to the national voluntary public health accreditation process. 2013.

19. Benzer JK, Beehler S, Miller C, Burgess JF, Sullivan JL, Mohr DC, et al. Grounded theory of barriers and facilitators to mandated implementation of mental health care in the primary care setting. Depress Res Treat. 2012;2012.

20. Day DV, Fleenor JW, Atwater LE, Sturm RE, McKee RA. Advances in leader and leadership development: A review of 25years of research and theory. LQ. 2014;25(1):63-82.

21. Forsberg E, Axelsson R, Arnetz B. The relative importance of leadership and payment system: Effects on quality of care and work environment. Health policy. 2004;69(1):73-82.

22. Smith PC, Anell A, Busse R, Crivelli L, Healy J, Lindahl AK, et al. Leadership and governance in seven developed health systems. Health policy. 2012;106(1):37-49.

23. Reeleder D, Goel V, Singer PA, Martin DK. Leadership and priority setting: the perspective of hospital CEOs. Health Policy. 2006;79(1):24-34

24. Peus C, Braun S, Frey D. Situation-based measurement of the full range of leadership model -Development and validation of a situational judgment test. LQ. 2013;24(5):777-95.

25. Ryan JC, Tipu SA. Leadership effects on innovation propensity: A two-factor full range leadership model. JBR. 2013;66(10):2116-29.

26. Mohammad Mosadegh Rad A, Hossein Yarmohammadian M. A study of relationship between managers' leadership style and employees' job satisfaction. Leadersh Health Serv. 2006;19(2):11-28.

27. Nasiripour AA, Delgoshaie B, Kalhor R, Kiaei MZ, Shahbahrami E, Tabatabaee SS. Effective factors on staffs' Job Satisfaction based on Herzberg Theory in Qazvin teaching hospitals. payavard salamat. 2013;7(4):354-65.

28. Faghisolouk F, Valinejadi A, Raeissi P. A Survey on the Relationship between Leadership Style and Strategy of Conflict Management among Top Managers of Urmia Hospitals: 2013. Journal of Hospital. 2014;13(3):109-15.

29. Dehghan Nayeri N, Nazari AA, Salsali M, Ahmadi F, Adib Hajbaghery M. Iranian staff nurses' views of their productivity and management factors improving and impeding it: a qualitative study. Nurs Health Sci. 2006;8(1):51-6.

30. Delkhosh Ka, Jafari M, Niroomand P. Servant leadeeship in hospital management: A focus on Naja vali-e-asr (A) hospital as a case study. 2013.

31. Ganji M, Dalvi M. The Impact of ethical leadership on job stress and occupation turnover intention in nurses of hospitals affiliated to Shahrekord University of Medical Sciences. J Shahrekord Univ Med Sci. 2014;16(1):121-8.

32. Sadeghi A, Goharloo Arkawaz A, Cheraghi F, Moghimbeigi A. Relationship between head nurses' servant leadership style and nurses' job satisfaction. Quarterly Journal of Nursing Management. 2015;4(1):0.

33. Saidi M, Karimi H. Relationship between nurse managers' emotional intelligence and their transformational leadership styles. Quarterly Journal of Nursing Management. 2012;1(2):63-9.

34. Sadeghifar J, Bahadori M, Baldacchino D, Raadabadi M, Jafari M. Relationship between career motivation and perceived spiritual leadership in health professional educators: a correlational study in Iran. Glob J Health Sci. 2014;6(2):145.

35. Khakdel Z, Mosadeghrad AM, Rahimi A, Jaafaripooyan E. Investigating the relationship between spiritual leadership and professional burnout among the staff of Ardebil hospitals, J Med 
Ethics Hist Med, 2016; 9 (1): 74-85. [Persian]

36. Hewison A, Morrell K. Leadership development in the English National Health Service: A counter narrative to inform policy. Int J Nurs Stud. 2014;51(4):677-88.

37.Faris N, Parry K. Islamic organizational leadership within a Western society: The problematic role of external context. Leadersh Q. 2011;22(1):132-51.

38. Al-Sawai A. Leadership of healthcare professionals: where do we stand? Oman Med J. 2013;28(4):285.

39. Kwamie A, van Dijk H, Agyepong IA. Advancing the application of systems thinking in health: realist evaluation of the Leadership Development Programme for district manager decision-making in Ghana. Health Res Policy Syst. 2014;12(1):29.

40. West M, Armit K, Loewenthal L, Eckert R, West T, Lee A. Leadership and leadership development in healthcare: the evidence base. London: FMLM. 2015

41. Hințea C, Cristina M, Țiclău T. Leadership and management in the health care system: Leadership perception in Cluj County children's hospital. TRAS. 2009;5(27):89-104

42. Hatef B, Mohammadi A, Yaribeygi H, Meftahi GH. Intensity and prevalence of source of stress in Iran. Health research. 2015;1(1):4357.

43. Byrne GJ, Bradley F. Culture's influence on leadership efficiency: How personal and national cultures affect leadership style. JBR. 2007;60(2):168-75.

44. Davies H, Mannion R, Jacobs R, Powell A, Marshall M. Exploring the relationship between senior management team culture and hospital performance. MCRR. 2007;64(1):46-65.

45. Dargahi H, Eskandari M, Shaham G. The Comparison between Present with Desired Organizational Culture in Tehran University of Medical Sciences' Hospitals. Payavard Salamat. 2010;4(2):72-87.

46. Mosadeghrad AM, Sokhanvar M. Organizational culture of selected hospitals of Tehran city. Journal of Hospital. 2017; 16 (2):46-57. [in Persian]

47. Wongprasit N. The leadership competencies model of private hospital directors in Thailand. HRD J. 2014;4(1):72-85.

48Reyes DJ, Bekemeier B, Issel LM. Challenges faced by public health nursing leaders in hyperturbulent times. Public Health Nurs. 2014;31(4):344-53.

49. Dehnavieh R, Ebrahimipour H, Jafari Zadeh M, Dianat M, Noori Hekmat S, Mehrolhassani MH. Clinical governance: The challenges of implementation in Iran. Int. j. hosp. res. 2013;2(1):1-10.

50. Robbins SP. Organization theory: The structure and design of organizations: Prentice-Hall; 1983.

51. Bikmoradi A, Brommels M, Shoghli A, Khorasani-Zavareh D, Masiello I. Identifying challenges for academic leadership in medical universities in Iran. Med Educ. 2010;44(5):459-67.

52. Kay Brazier D. Influence of contextual factors on health-care leadership. LODJ. 2005;26(2):128-40.

53. Atefi Manesh P, Saleh Ardestani A, Kermani B, Rezapoor A, Sarabi Asiabar A. The relation characteristics of personality of managers working in Iran University of Medical Sciences with success and desirable job. MJIRI. 2015 Jan 15;29(1):580-5.

54. Fleming ML, Kayser-Jones J. Assuming the mantle of leadership: Issues and challenges for directors of nursing. $\mathrm{J}$ Gerontol Nurs. 2008;34(11):18-25.

55. Abbasi SM. Examining the role of communication skills and organizational structure in predicting job satisfaction in Taksam Company. Journal of Amin vision. 2015;1(3):24-30.

56. Dye CF, Garman AN. Exceptional leadership: 16 critical competencies for healthcare executives. HAP; 2015.

57. Ardestani AS, Sarabi Asiabar A, Ebadifard Azar F, Abtahi SA. The relationship between hospital managers' leadership style and effectiveness with passing managerial training courses. MJIRI. 2016 Jan 15;30(1):1219-24

58. McAlearney AS, Garman AN, Song PH, McHugh M, Robbins J, Harrison MI. High-performance work systems in health care management, part 2: qualitative evidence from five case studies. HCMR. 2011;36(3):214-26. 